Published in final edited form as:

J Pediatr Gastroenterol Nutr. 2012 May ; 54(5): 580-587. doi:10.1097/MPG.0b013e31824711b7.

\title{
Congenital Hepatic Fibrosis and Autosomal Recessive Polycystic Kidney Disease
}

\author{
Arvind Srinath and Benjamin L. Shneider \\ Division of Pediatric Gastroenterology, Hepatology, and Nutrition, Children's Hospital of \\ Pittsburgh of UPMC, Pittsburgh, PA.
}

\section{Abstract}

Objectives-The published natural history of congenital hepatic fibrosis (CHF) was examined to inform clinical decision making in autosomal recessive polycystic kidney disease (ARPKD).

\begin{abstract}
Methods-A systematic literature search of the data on CHF, ARPKD, Caroli disease, Caroli syndrome, and type $\mathrm{V}$ choledochal cyst was performed to extract data related to portal hypertension, infection, malignancy, mortality, and transplantation.
\end{abstract}

\begin{abstract}
Results-Information related to 1230 patients with CHF was extracted from 155 articles. Median and mean age at diagnosis were 2 and 11.2 years, respectively. Median and mean time followed after diagnosis were 5.0 and 7.5 years, respectively (range $0-38$ years). Sequelae of portal hypertension $(n=409)$, cholangitis $(n=152)$, and malignancy $(n=21)$ were noted. The nature of the portal hypertension was similar to that in other pediatric conditions (164 with varices, 74 bleeding varices, 81 underwent portosystemic shunting). Documented cholangitis was fatal in 3 of 23 children who were infected after renal transplantation. Twenty-one patients developed hepatobiliary cancer, with the majority having cholangiocarcinoma $(n=19)$. Cholangiocarcinoma (CCA) was predominant in individuals older than 40 years with either Caroli syndrome or isolated CHF, not ARPKD (median and mean age at CCA diagnosis were 70.3 and 60.1 years, respectively; range 33-75 years). There was a relative paucity of data on combined liver-kidney transplantation.
\end{abstract}

Conclusions-Clinical decision making in ARPKD should reflect an understanding of the potential issues emanating from CHF. Accepted pediatric specific approaches to portal hypertension are warranted but must take into consideration the stage of renal insufficiency and potential plans for renal transplantation. Cholangitis is a major issue and necessitates anticipatory guidance and awareness. CCA, although a dreaded complication, does not appear to be a major issue during childhood. The indications for liver and combined liver-kidney transplantation are controversial and warrant further analysis.

Copyright ( 2012 by European Society for Pediatric Gastroenterology, Hepatology, and Nutrition and North American Society for Pediatric Gastroenterology, Hepatology, and Nutrition

Address correspondence and reprint requests to Benjamin L. Shneider, MD, Division of Pediatric Gastroenterolgy, Hepatology, and Nutrition, Children's Hospital of Pittsburgh of UPMC, 4401 Penn Ave, Pittsburgh, PA 15224 (benjamin.shneider@ chp.edu).

Supplemental digital content is available for this article. Direct URL citations appear in the printed text, and links to the digital files are provided in the HTML text of this article on the journal's Web site (www.jpgn.org).

The authors report no conflicts of interest. 


\section{Keywords}

cholangiocarcinoma; cholangitis; portal hypertension; transplantation; varices

Autosomal recessive polycystic kidney disease (ARPKD)/congenital hepatic fibrosis (CHF) is a fibrocystic disease affecting mainly the kidneys and liver. It is characterized by fusiform dilatations of the renal collecting duct and ductal plate malformation of the liver. The incidence is approximately 1:20,000 live births. The majority of cases are caused by mutations in the $P K H D l$ gene, which encodes for fibrocystin/polycystin. This protein is expressed by the renal and biliary epithelium and is postulated to maintain 3-dimensional tubular architecture (1). ARPKD can be divided into 4 subgroups (2). The first group, "perinatal," presents in infancy with severe renal disease, congestive heart failure, and pulmonary hypoplasia. The second group, "neonatal," has progressive renal disease, whereas the third ("infantile") and fourth ("juvenile") groups have less severe renal disease and more complications from CHF. CHF typically occurs in ARPKD (3). Two registries have examined the nature and prevalence of liver disease in ARPKD $(4,5)$. CHF can be an isolated lesion (isolated CHF, iCHF) or can occur in ARPKD, Caroli syndrome, and other inherited and noninherited conditions (6). CHF in the setting of ARPKD (and related conditions) can lead to complications that are related primarily to portal hypertension and recurrent cholangitis $(1,3)$. There is growing concern about the role of CHF in the development of sepsis for patients with ARPKD who have undergone renal transplantation (7). There is also the potential risk of development of cholangiocarcinoma in individuals with chronic biliary disease. Because CHF in ARPKD is "curable" via liver transplantation, combined liver-kidney transplantation as a potentially more definitive therapy has been suggested. Clinical decision making in ARPKD/CHF is particularly difficult given the interrelation of the 2 diseased organ systems. The indications for and timing of liver transplantation or nontransplant surgeries such as portosystemic shunting in ARPKD are not clear. A clearer understanding of the natural history of CHF may inform this particularly difficult clinical decision making.

\section{METHODS}

A systematic review of MEDLINE in the English language was performed in separate searches for the years ranging from 1950 to 2010. The first search included key words "autosomal," "recessive," "polycystic," "kidney," and "disease" with the Boolean operators and and and/or with search term "ARPKD." The next search included key words "congenital," "hepatic," and "fibrosis" with the Boolean search term and. The next search included key words "Caroli disease" and "Caroli syndrome" with the Boolean search term or. Subsequently, key words "type 5 choledochal cyst" and "type V choledochal cyst" with the Boolean search term or were examined. The next search included the phrases "congenital hepatic fibrosis and transplant," "autosomal recessive polycystic kidney disease and transplant," "Caroli and transplant," and "choledochal cyst and transplant" with the Boolean search term or. Penultimately, the following search included the key words "autosomal recessive polycystic kidney disease," "Caroli disease," "Caroli syndrome," and "choledochal cyst," with each term separated with the key word "shunt" and with the 
Boolean search term and. Lastly, a search under the key words "congenital bile duct cyst" was performed. Excluded from this search were papers describing patients with known or suspected (based on the constellation of anomalies) genetic syndromes, because the prognosis of these syndromes may have been affected by the systemic nature of the genetic disorder.

Data analysis was descriptive. Notably, a lack of negative or affirmative description for morbidities within the types of $\mathrm{CHF}$ conditions was documented. In general, a lack of description of a morbidity was not assumed to exclude that morbidity but was viewed as indeterminant for prevalence of the complication. Specifically, if a condition within the diseases examined was noted in an affirmative or negative fashion, then that condition was noted as "reported." If there is an affirmative description for a "reported" condition, then that condition was noted as "present." Descriptive data were typically presented as the median with range because it was nonparametric. Caroli disease was defined as multifocal cystic dilatation of the intrahepatic and potentially extrahepatic bile ducts. It has a high incidence of concurrent cystic renal abnormalities. Caroli syndrome consists of features of Caroli disease associated with hepatic fibrosis. Because the difference between Caroli disease and Caroli syndrome is not entirely clear in the literature and may be dependent upon the nature of investigation of the liver disease, the conditions were grouped together in the analysis as Caroli disease/syndrome. Portal hypertension was clinically noted via use of the term or its known clinical sequelae, that is, splenomegaly, esophageal varices, and hypersplenism. None of the articles reviewed described the aforementioned physical findings without using those terms, nor did they use those terms and describe them incorrectly. Similarly, hypersplenism, if not specifically noted, was defined by the presence of both leucopenia (white blood cell count <4.0) and thrombocytopenia (platelet count $<150,000)$.

\section{RESULTS}

A total of 211 articles were identified and reviewed (the full list is available online only at http://links.lww.com/MPG/A88). Fifty-six were excluded for not being or referring to specific case series or case reports. A total of 1230 patient data were tabulated. The median age at diagnosis was 2 years with a range between birth and 75 years. The male:female ratio of the entire dataset (sex reported in 989 individuals) was 472 males:517 females. There were 146 single-center studies and 9 multicenter studies. One hundred fifty studies were retrospective, and 5 studies were prospective. The mean and median duration of follow-up was 5.0 and 7.5 years, respectively, with a range of 0 to 38 years. In only 164 reports was there documentation of the time of follow-up. Table 1 summarizes the distribution of reviewed conditions associated with $\mathrm{CHF}$, their age at diagnosis, most common diagnostic modality, and most common presenting symptom/condition. Table 2 summarizes the clinical morbidities associated with the reviewed conditions and their onset.

\section{Portal Hypertension}

A majority of the patients who had portal hypertension had ARPKD. This proportion mirrored the fact that a majority of the patients examined in the present study had ARPKD 
(64\%). Portal hypertension was found in a high percentage of individuals with iCHF, which is likely to be a reflection of the most common mode of clinical presentation of iCHF (Table 2). The grids in Table 2 delineate the published literature on CHF. For example, there were 118 individuals with iCHF, in 87 cases there was definitive information as to the presence or absence of portal hypertension, and in 84 of these cases, portal hypertension was present. Thus, depending on the chosen denominator, portal hypertension presented in $97 \%$ or $71 \%$ of individuals with iCHF. In 21 cases, age at diagnosis of portal hypertension was noted, with a median age of 12 years (range between 0.3 and 41 years). The time of identification of portal hypertension coincided with the time of diagnosis of iCHF. In 1 case, portal hypertension was identified 30 years before the diagnosis of iCHF.

Sequelae of portal hypertension were examined, including hypersplenism, esophageal varices, ascites, and hepatopulmonary syndrome. Overall, hypersplenism and varices were relatively common complications, whereas ascites, hepatopulmonary syndrome, and encephalopathy were uncommon. In 74 cases, hemorrhage from esophageal varices was reported (Table 2, footnote*). The age at bleeding and the time from documentation of CHF to bleeding were infrequently reported. In 58 cases, interventions for the varices were described and included primarily shunts (37 patients, including 2 transjugular intrahepatic portosystemic shunt procedures) and sclerotherapy (15 patients). Other interventions included band ligation ( 6 patients). Several patients had $>1$ procedure performed for esophageal varices, including portosystemic shunt after sclerotherapy ( 5 patients) and portosystemic shunt after band ligation ( 2 patients). Many of these reports emanated from a time when endoscopic band ligation was not routinely performed. In 16 patients with bleeding esophageal varices, there was no description of intervention for the varices. Most reports of ascites were within the ARPKD population. Age at diagnosis of ascites was rarely reported. Hepatopulmonary syndrome was scantly noted, and all of the reported cases had iCHF. It is not clear whether these patients were screened for evidence of hepatopulmonary syndrome.

\section{Portosystemic Shunting}

Table 3 documents the prevalence, type, and outcome of portosystemic shunting in the examined conditions with CHF. Overall, 81 patients underwent some type of portosystemic shunting procedure, with the largest number of procedures being performed in the setting of ARPKD. The most common procedure was a splenorenal shunt. Twenty-five of 34 patients had improvement. There was a paucity of data describing time to improvement after shunt and shunt morbidity. Parameters that were noted included improving white blood cell count and platelet count (10 patients), no further episodes of variceal bleeding ( 7 patients, not all of whom had documented repeat endoscopic findings), regression of splenomegaly ( 5 patients), and regression of esophageal varices (2 patients). Morbidity after portosytemic shunting was noted in 7 patients: gastrointestinal bleeding (4 patients) and encephalopathy (3 patients). Eleven patients had portosystemic shunts without evidence of variceal bleeding. In 5 cases, the indication was for hypersplenism, 4 had preemptive portosystemic shunting before renal transplantation, and 1 patient had a portosystemic shunt for ascites. None of the patients underwent splenic embolization for hypersplenism. 


\section{Encephalopathy}

In 1 case series (8), both patients with ARPKD had concerns for worsening hepatic encephalopathy in the setting of end-stage renal disease treated by portosystemic shunting (splenorenal and mesocaval, respectively). In the patient described by Hodgson et al (9) with iCHF, renal dysfunction was noted by low creatinine clearance. Lillegard (10) reported encephalopathy in their patients with iCHF. Their patients' renal function and timing of encephalopathy (before or after portosystemic shunting) were unclear. Both patients with ARPKD and encephalopathy described by Khan et al (7) had encephalopathy several days after isolated renal transplantation. It was unclear how well their graft was functioning at that time. In all of these cases, it is possible that renal failure may have been comorbid in developing encephalopathy.

\section{Cholangitis and Sepsis}

Within the conditions studied, cholangitis was noted mainly in Caroli disease/syndrome and ARPKD (Table 2); however, there were 7 cases of cholangitis in individuals with "iCHF." In those individuals with cholangitis, there was a high likelihood that the problem was recurrent.

\section{Hepatobiliary Cancer}

We suspect that the overall prevalence of hepatobiliary cancer is close to 21 of 1230 (2\%) because it is unlikely that hepatobiliary cancer would be unreported. Given the sparse reports of hepatoblastoma and either iCHF or $\operatorname{ARPKD~}(n=2)$, we believe that the association is more coincidental or related to prematurity rather than specifically related to these conditions. Of the 21 cases of hepatobiliary cancer, 19 were cholangiocarcinoma. Fifty-three percent of patients with cholangiocarcinoma had Caroli disease/syndrome (10/19), 37\% (7/19) had iCHF, 5\% (1/19) had ARPKD, and 5\% (1/19) had type V choledochal cyst. This distribution is skewed toward a population that is not as well represented in this analysis, which may shed light on the pathophysiology of cholangiocarcinoma in relation to conditions associated with CHF. Age at diagnosis of cholangiocarcinoma can be seen in Figure 1. Of note and as expected, the vast majority of patients were older than 40 years (median and mean age at CCA diagnosis were 58.8 and 60 years, respectively [range 33-75 years]).

There were 4 cases of cholangiocarcinoma (with metastases at diagnosis) in iCHF (11-14). There was only 1 patient (13) in whom the malignancy was diagnosed in the extrahepatic bile ducts. Totkas and Hohenberger (15) described a male patient who presented with cholangiocarcinoma as an incidental finding during screening ultrasound for cardiac arrhythmia. The disease was nonmetastatic, and the patient was found to have left-sided Caroli disease. The duration of follow-up for this patient is not known, but he underwent segmental hepatic resection (segments II, III, IVb) without complication. Within smaller bile ducts pigmented concretions and focal abscess formation were found (the patient had obstructive gallstones in the past but no documented history of cholangitis). The patient described by Abdalla et al (16) also had left-sided Caroli disease, with cholangiocarcinoma incidentally found upon left lobar resection (secondary to recurrent cholangitis). It is unclear how long this patient was studied, but there was no note of mortality postresection. 
Vlachogiannakos et al (17) also described a male patient who had a left hepatic lobectomy secondary to recurrent cholangitis and magnetic resonance cholangiopancreatography findings that were consistent with monolobar Caroli disease. The patient's pathology was notable for cholangiocarcinoma. Follow-up imaging several months later revealed a hilar tumor with stenosis of the common hepatic duct. The patient died 2 months later. The case of monolobar (left-sided) Caroli disease described by Terada et al (18) was remarkable for extrahepatic cholangiocarcinoma. The patient described also had recurrent cholangitis.

\section{Mortality}

Table 4 summarizes the issue of mortality in conditions associated with CHF. Because the percentage values in this table can be misleading, the inclusion of actual patient numbers more fully illustrates that a small number of the patients in the present study died. Of the 78 reported mortality causes, $37 \%$ were sepsis, $15 \%$ complications related to cholangiocarcinoma, $6 \%$ bleeding esophageal varices, and 5\% respiratory failure related to portopulmonary hypertension. There were 3 cases in which cause of death was "liver failure" $(4,7,19)$. Details documenting true synthetic liver failure were not reported. Of the 29 cases with mortality from sepsis, 20 of 29 had ARPKD, 2 patients had Caroli syndrome, and 1 patient had iCHF. In 12 of the 20 patients with ARPKD who died of sepsis, death occurred after isolated renal transplantation.

\section{Transplantation}

Of the 1230 patients, 538 had reported data on transplantation (Fig. 2). A total of 287 of those patients had either single organ (kidney $[n=91]$ or liver $[n=173]$ ) or combined transplantation $(\mathrm{n}=23)$. Three patients had renal transplants before combined transplant (including retransplant of kidney). Order of organ transplantation was documented in 5 cases; in 4, liver transplantation was first. Ninety-five percent of the patients who had isolated renal transplantation had ARPKD. Eighty-seven percent (151/173) of patients with isolated liver transplantation had Caroli disease/syndrome; 9\% had ARPKD.

The distribution of conditions between those who had combined liver-kidney transplantation was roughly even between ARPKD and Caroli disease/syndrome (11/23 and 12/23, respectively). It is known that Caroli disease/syndrome can be associated with varying degrees of renal cysts, ARPKD, nephrocalcinosis, interstitial fibrosis, and renal failure (2022). In the cohort that had isolated renal transplantation, there were 34 reports on the presence/absence of posttransplant sepsis. Twenty-three of 34 patients became septic. Thirteen of the 23 patients died. Three of the 13 patients were "diagnosed" as having cholangitis. Only 1 of the deceased patients had report of liver enzymes and those were minimally deranged.

In the isolated liver transplantation cohort, there were 30 patients with likely combination ARPKD/Caroli disease/Caroli syndrome (23). Of the 7 patients who died of sepsis after transplantation ( 3 before 1 year, 4 after 1 year), 5 of them had perioperative cholangitis, although this morbidity was not stratified by CHF subtype. It is unclear whether these patients had a duct-to-duct anastamosis of an abnormal extrahepatic bile duct. The indication for transplant was recurrent cholangitis in only 1 patient in this cohort. In the patients with 
isolated liver transplants, posttransplant renal function was documented in 5 patients (2426). The 3 patients with ARPKD described by Arikan et al (24) had improved renal function 18 months after liver transplantation. The patient with iCHF studied by Dehghani (25) had normal renal function 7 months after liver transplant. Renal function acutely declined after liver transplantation in the patient described by Meier et al (26), and was believed to be secondary to acyclovir used for the treatment of varicella zoster virus infection.

In the combined liver-kidney transplantation cohort, 11 patients had ARPKD. In the 4 cases of ARPKD in which it was noted, 3 cases had liver transplant first. Morbidity was noted in 2 cases after the first transplant. In 1 case with primary renal transplantation, there was recurrent cholangitis starting 24 months posttransplant. In the second case with primary liver transplantation, peritonitis was a complication. Four of the 23 patients who underwent combined transplantation died, 2 from liver failure of unclear cause and 2 from complications related to graft failure.

\section{DISCUSSION}

Clinical decision making in the setting of CHF and ARPKD is complex and not well established in the literature (27). The renal and liver diseases advance at independent rates, and manifestations of problems from either organ system have the potential to influence the outcome of organ-specific interventions. Carefully collected prospective data would help inform these decisions. Unfortunately, those data do not exist, especially as they pertain to liver disease in CHF. The purpose of the present analysis was to assess the existing literature relative to this issue. The limitations of such an analysis are obvious, but it serves as a useful starting point and perhaps highlights issues for future prospective investigation.

The major liver-related issues in CHF are complications of portal hypertension, cholangitis, and a potential increased predisposition to the development of cholangiocarcinoma. Each of these issues raises distinct questions and implications for planning for the potential for renal replacement therapy. In addition, the approach to these liver issues must take into consideration the state and rate of progress of renal insufficiency.

Portal hypertension in CHF is associated with well-known potential clinical complications, namely, clinically relevant splenomegaly, hypersplenism, variceal hemorrhage, ascites, spontaneous bacterial peritonitis, hepatopulmonary syndrome, portopulmonary hypertension, and hepatic encephalopathy. Problems of splenomegaly, hypersplenism, and variceal hemorrhage predominate. Standard pediatric-specific surveillance and initial management approaches to these problems in children are reasonable in light of this collective experience (28). The development of ascites is uncommon and should trigger an assessment for an additional underlying issue such as portal vein thrombosis or loss of peritoneal exchange space caused by recurrent peritonitis and/or a history of peritoneal dialysis.

CHF and associated conditions are somewhat distinct from many other chronic pediatric liver diseases in that they are not typically associated with progressive hepatic insufficiency, although there are rare exceptions (29-32). As such, indications for consideration of liver 
transplantation may be different from those for other chronic pediatric liver disorders. Most children with $\mathrm{CHF}$ and recurrent variceal hemorrhage do not have significant hepatic dysfunction, although they may have evolving renal insufficiency. This evolving renal insufficiency has the potential to complicate efforts to use portosystemic shunting as a treatment option for refractory recurrent variceal hemorrhage or other complications of portal hypertension. The existing literature reveals a few cases in which this is an issue (810), although, in general, this may be more theoretical than real in most circumstances. Surgical or interventional portosystemic shunting is not necessarily contraindicated in CHF/ ARPKD, but it needs to be carefully considered in the context of the existing state and pace of the renal disease. We do not know the effect of portosystemic shunting on the renal disease, but we do know that calcineurin inhibitors used in the context of liver transplantation can hasten the development of renal insufficiency (33-35). If renal replacement therapy is believed to be necessary in the near future, then combined transplantation needs to be carefully assessed as an option. The incremental risk of liver transplantation in addition to renal transplantation is real and needs to be considered in the risk-benefit analysis.

It is clear that cholangitis is a major issue in CHF and has profound implications in clinical decision making in ARPKD. It is not necessarily easily diagnosed and must be carefully considered by nephrologists, gastroenterologists, and transplant physicians. Families of children with ARPKD must be carefully instructed as to the subtle manifestations of cholangitis and the potential devastating consequences of late diagnosis of the problem. The diagnosis of cholangitis has implications for transplant decisions when a child needs renal replacement therapy. More important, the development of cholangitis after renal transplantation can be fatal, we believe, as a result more of late identification than the risks of immunosuppression. The description of abnormalities of the extrahepatic bile duct in ARPKD and iCHF may explain the unexpected problems with cholangitis after isolated liver transplantation in CHF and associated conditions $(36,37)$. Careful imaging of the extrahepatic bile duct should be performed before liver transplantation, with a low threshold to not use the native bile duct of the recipient. The finding of an abnormal biliary tree in a child with ARPKD, who has not had documented complications related to the cholangiopathy, raises difficult questions, in particular, related to the advisability of liver transplantation if a renal transplant is indicated. The present literature does not adequately illuminate this important question and prospective registry data are clearly needed.

The issue of a potential increased risk for the development of cholangiocarcinoma is harrowing. Once diagnosed, the prognosis is typically grim and surveillance approaches are inadequate (38-42). The present analysis was surprising in its findings related to cholangiocarcinoma. First, nearly half of the reported cases were in purported iCHF (1114,43). This suggests that the concept of iCHF is likely a pathophysiologic misnomer and that many of these individuals have underlying cholangiopathies. Unfortunately, many of these cases were reported before the advent of techniques such as magnetic resonance cholangiopancreatography (or even endoscopic retrograde cholangiopancreatography), so it is unclear how well the intra- and extrahepatic biliary tree was evaluated in these patients. As a corollary, one must consider all of the individuals with CHF to be at risk for cholangitis. The majority of the other cases of cholangiocarcinoma occurred in Caroli 
disease $(15,16,44,45)$ and not in classical ARPKD (46). Most were incidental findings at the time of liver lobe resection. The prevalence of cholangiocarcinoma in this population raises the question of screening utility, either biochemically or radiologically. Present technologies are neither sensitive nor specific enough to be effective $(47,48)$. In addition, biliary disease and/or cholangitis can artifactually raise many of the biochemical parameters available as screening tools for cholangiocarcinoma $(49,50)$. In light of the rarity of this complication in childhood, routine screening for cholangiocarcinoma cannot be recommended in children with CHF. In addition, the potential risk of cholangiocarcinoma should not influence clinical decision making in childhood.

\section{CONCLUSIONS}

Patients with CHF are prone to develop cholangitis and complications of portal hypertension. They also are at risk for developing cholangiocarcinoma. These tendencies, when compiled with associated renal disease, can complicate decisions regarding therapeutic approaches. Complications of portal hypertension lead to significant morbidity. Cholangitis may not present with a typical biochemical picture and is thus difficult to diagnose in this population. The predisposition to cholangitis in patients with CHF has significant bearing on their disease course, in particular toward transplant organ type(s), timing, potentially immunosuppression, and overall outcome. The unexpected incidence of cholangiocarcinoma in this population is unsettling, although the late onset is less an issue in pediatrics. This analysis covered a large body of literature, which was primarily retrospective. Given the obvious limitations of such an analysis, prospective clinical registries of children with ARPKD are needed to inform future clinical decision making.

\section{REFERENCES}

1. Turkbey B, Ocak I, Daryanani K, et al. Autosomal recessive polycystic kidney disease and congenital hepatic fibrosis (ARPKD/CHF). Pediatr Radiol. 2009; 39:100-111. [PubMed: 19089418]

2. Blyth H, Ockenden BG. Polycystic disease of kidney and liver presenting in childhood. J Med Genet. 1971; 8:257-284. [PubMed: 5097134]

3. Gunay-Aygun M, Avner ED, Bacallao RL, et al. Autosomal recessive polycystic kidney disease and congenital hepatic fibrosis: summary statement of a first National Institutes of Health/Office of Rare Diseases Conference. J Pediatr. 2006; 149:159-164. [PubMed: 16887426]

4. Davis ID, Ho M, Hupertz V, et al. Survival of childhood polycystic kidney disease following renal transplantation: the impact of advanced hepatobiliary disease. Pediatr Transplant. 2003; 7:364-369. [PubMed: 14738296]

5. Guay-Woodford LM, Desmond RA. Autosomal recessive polycystic kidney disease: the clinical experience in North America. Pediatrics. 2003; 111:1072-1080. [PubMed: 12728091]

6. Shorbagi A, Bayraktar Y. Experience of a single center with congenital hepatic fibrosis: a review of the literature. World J Gastroenterol. 2010; 16:683-690. [PubMed: 20135715]

7. Khan K, Schwarzenberg SJ, Sharp HL, et al. Morbidity from congenital hepatic fibrosis after renal transplantation for autosomal recessive polycystic kidney disease. Am J Transplant. 2002; 2:360 365. [PubMed: 12118859]

8. Tsimaratos M, Cloarec S, Roquelaure B, et al. Chronic renal failure and portal hypertension-is portosystemic shunt indicated. Pediatr Nephrol. 2000; 14:856-858. [PubMed: 10955945]

9. Hodgson HJ, Davies DR, Thompson RP. Congenital hepatic fibrosis. J Clin Pathol. 1976; 29:11-16. [PubMed: 1249246] 
10. Lillegard JB, Hanna AM, McKenzie TJ, et al. A single-institution review of portosystemic shunts in children: an ongoing discussion. HPB Surg. 2010; 2010:964597. [PubMed: 20467465]

11. Daroca PJ, Tuthill R, Reed RJ. Cholangiocarcinoma arising in congenital hepatic fibrosis. A case report. Arch Pathol. 1975; 99:592-595. [PubMed: 179515]

12. Parker RG. Fibrosis of the liver as a congenital anomaly. J Pathol Bacteriol. 1956; 71:359-368. [PubMed: 13398881]

13. Scott J, Shousha S, Thomas HC, et al. Bile duct carcinoma: a late complication of congenital hepatic fibrosis: case report and review of literature. Am J Gastroenterol. 1980; 73:113-119. [PubMed: 6249119]

14. Yamato T, Sasaki M, Hoso M, et al. Intrahepatic cholangiocarcinoma arising in congenital hepatic fibrosis: report of an autopsy case. J Hepatol. 1998; 28:717-722. [PubMed: 9566842]

15. Totkas S, Hohenberger P. Cholangiocellular carcinoma associated with segmental Caroli's disease. Eur J Surg Oncol. 2000; 26:520-521. [PubMed: 11016478]

16. Abdalla EK, Forsmark CE, Lauwers GY, et al. Monolobar Caroli's disease and cholangiocarcinoma. HPB Surg. 1999; 11:271-276. [PubMed: 10468120]

17. Vlachogiannakos J, Potamianos S, Triantos C, et al. Monolobar Caroli's disease complicated by cholangiocarcinoma in a 70-year-old man, previously asymptomatic. Gastrointest Endosc. 2004; 60:297-300. [PubMed: 15278068]

18. Terada T, Moriki T. Monolobar hepatobiliary fibropolycystic disease. Pathol Oncol Res. 2011; 17:159-165. [PubMed: 20512666]

19. Kashtan CE, Primack WA, Kainer G, et al. Recurrent bacteremia with enteric pathogens in recessive polycystic kidney disease. Pediatr Nephrol. 1999; 13:678-682. [PubMed: 10502126]

20. Lakshmi Y, Devi BV, Sarala S. Renal cysts in Caroli’s disease. Indian J Nephrol. 2010; 20:54. [PubMed: 20535274]

21. Mrowka C, Adam G, Sieberth HG. Caroli's syndrome associated with medullary sponge kidney and nephrocalcinosis. Nephrol Dial Transplant. 1996; 11:1142-1145. [PubMed: 8671984]

22. Toprak O, Uzum A, Cirit M, et al. Oral-facial-digital syndrome type 1. Nephrol Dial Transplant. 2006; 21:1705-1709. [PubMed: 16384823]

23. Habib S, Shakil O, Couto OF, et al. Caroli's disease and orthotopic liver transplantation. Liver Transpl. 2006; 12:416-421. [PubMed: 16498655]

24. Arikan C, Ozgenc F, Akman SA, et al. Impact of liver transplantation on renal function of patients with congenital hepatic fibrosis associated with autosomal recessive polycystic kidney disease. Pediatr Transplant. 2004; 8:558-560. [PubMed: 15598323]

25. Dehghani SM, Nikeghbalian S, Eshraghian A, et al. New-onset diabetes mellitus presenting with diabetic ketoacidosis after pediatric liver transplantation. Pediatr Transplant. 2009; 13:536-539. [PubMed: 19207220]

26. Meier C, Deutscher J, Müller S, et al. Successful liver transplantation in a child with Caroli's disease. Pediatr Transplant. 2008; 12:483-486. [PubMed: 18179642]

27. Shneider BL, Magid MS. Liver disease in autosomal recessive polycystic kidney disease. Pediatr Transplant. 2005; 9:634-639. [PubMed: 16176423]

28. Shneider BL, Emre S, Groszman R, et al. Expert pediatric opinion on the report of the Baveno IV consensus workshop on methodology of diagnosis and therapy in portal hypertension. Pediatr Transplant. 2006; 10:893-907. [PubMed: 17096755]

29. Arbeiter A, Büscher R, Bonzel KE, et al. Nephrectomy in an autosomal recessive polycystic kidney disease (ARPKD) patient with rapid kidney enlargement and increased expression of EGFR. Nephrol Dial Transplant. 2008; 23:3026-3029. [PubMed: 18503009]

30. Beaunoyer M, Snehal M, Li L, et al. Optimizing outcomes for neonatal ARPKD. Pediatr Transplant. 2007; 11:267-271. [PubMed: 17430481]

31. Keane F, Hadzić N, Wilkinson ML, et al. Neonatal presentation of Caroli's disease. Arch Dis Child Fetal Neonatal Ed. 1997; 77:F145-F146. [PubMed: 9377141]

32. Mourad W, Khalaf H, Tulbah A, et al. Clinicopathologic features of hepatic neoplasms in explanted livers: a single institution experience. Ann Saudi Med. 2007; 27:437-441. [PubMed: 18059117] 
33. Gonwa TA, Mai ML, Melton LB, et al. End-stage renal disease (ESRD) after orthotopic liver transplantation (OLTX) using calcineurin-based immunotherapy: risk of development and treatment. Transplantation. 2001; 72:1934-1939. [PubMed: 11773892]

34. Neau-Cransac M, Morel D, Bernard PH, et al. Renal failure after liver transplantation: outcome after calcineurin inhibitor withdrawal. Clin Transplant. 2002; 16:368-373. [PubMed: 12225434]

35. Pawarode A, Fine DM, Thuluvath PJ. Independent risk factors and natural history of renal dysfunction in liver transplant recipients. Liver Transpl. 2003; 9:741-747. [PubMed: 12827563]

36. Goilav B, Norton KI, Satlin LM, et al. Predominant extrahepatic biliary disease in autosomal recessive polycystic kidney disease: a new association. Pediatr Transplant. 2006; 10:294-298. [PubMed: 16677351]

37. Perisic VN, Mihailovic T, Filipovic D. Congenital hepatic fibrosis, bile duct abnormality, long pancreaticobiliary common channel, and pancreatitis. J Pediatr Gastroenterol Nutr. 1988; 7:790 791. [PubMed: 3183887]

38. Gatto M, Alvaro D. New insights on cholangiocarcinoma. World J Gastrointest Oncol. 2010; 2:136-145. [PubMed: 21160821]

39. Kanaan N, Goffin E, Pirson Y, et al. Carbohydrate antigen 19-9 as a diagnostic marker for hepatic cyst infection in autosomal dominant polycystic kidney disease. Am J Kidney Dis. 2010; 55:916922. [PubMed: 20189277]

40. Morris-Stiff G, Bhati C, Olliff S, et al. Cholangiocarcinoma complicating primary sclerosing cholangitis: a 24-year experience. Dig Surg. 2008; 25:126-132. [PubMed: 18446034]

41. Patel T, Singh P. Cholangiocarcinoma: emerging approaches to a challenging cancer. Curr Opin Gastroenterol. 2007; 23:317-323. [PubMed: 17414849]

42. Schulick RD. Primary sclerosing cholangitis: detection of cancer in strictures. J Gastrointest Surg. 2008; 12:420-422. [PubMed: 17999125]

43. Yönem O, Ozkayar N, Balkanci F, et al. Is congenital hepatic fibrosis a pure liver disease? Am J Gastroenterol. 2006; 101:1253-1259. [PubMed: 16771946]

44. Kassahun WT, Kahn T, Wittekind C, et al. Caroli's disease: liver resection and liver transplantation. Experience in 33 patients. Surgery. 2005; 138:888-898. [PubMed: 16291390]

45. Zangger P, Grossholz M, Mentha G, et al. MRI findings in Caroli's disease and intrahepatic pigmented calculi. Abdom Imaging. 1995; 20:361-364. [PubMed: 7549744]

46. Fonck C, Chauveau D, Gagnadoux MF, et al. Autosomal recessive polycystic kidney disease in adulthood. Nephrol Dial Transplant. 2001; 16:1648-1652. [PubMed: 11477168]

47. Nehls O, Gregor M, Klump B. Serum and bile markers for cholangiocarcinoma. Semin Liver Dis. 2004; 24:139-154. [PubMed: 15192787]

48. Van Beers BE. Diagnosis of cholangiocarcinoma. HPB (Oxford). 2008; 10:87-93. [PubMed: 18773062]

49. Albert MB, Steinberg WM, Henry JP. Elevated serum levels of tumor marker CA19-9 in acute cholangitis. Dig Dis Sci. 1988; 33:1223-1225. [PubMed: 3168694]

50. Ong SL, Sachdeva A, Garcea G, et al. Elevation of carbohydrate antigen 19.9 in benign hepatobiliary conditions and its correlation with serum bilirubin concentration. Dig Dis Sci. 2008; 53:3213-3217. [PubMed: 18465243] 


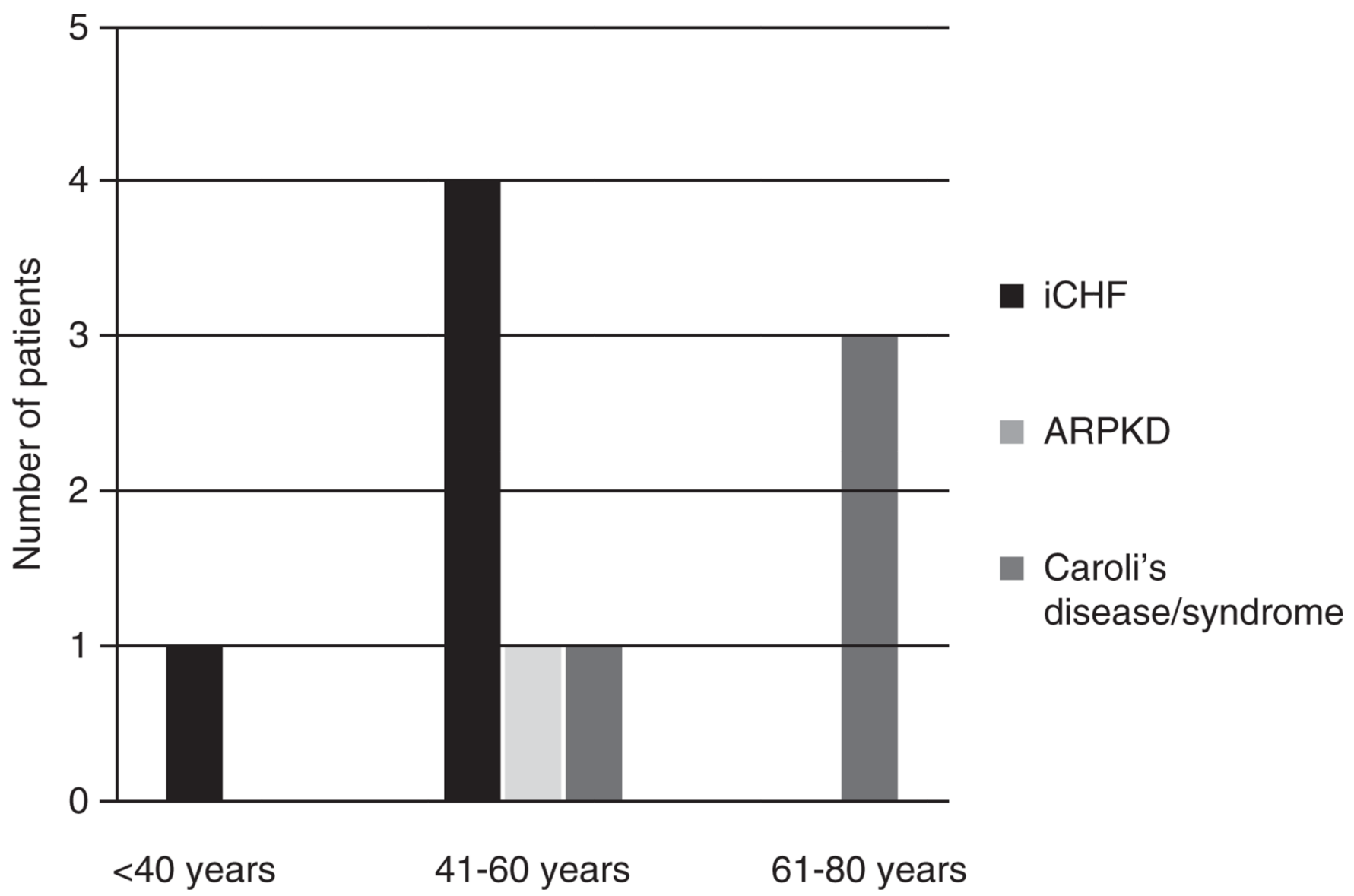

FIGURE 1.

Age at diagnosis of cholangiocarcinoma in congenital hepatic fibrosis. The number of patients, their age at diagnosis, and their disease type are shown. 


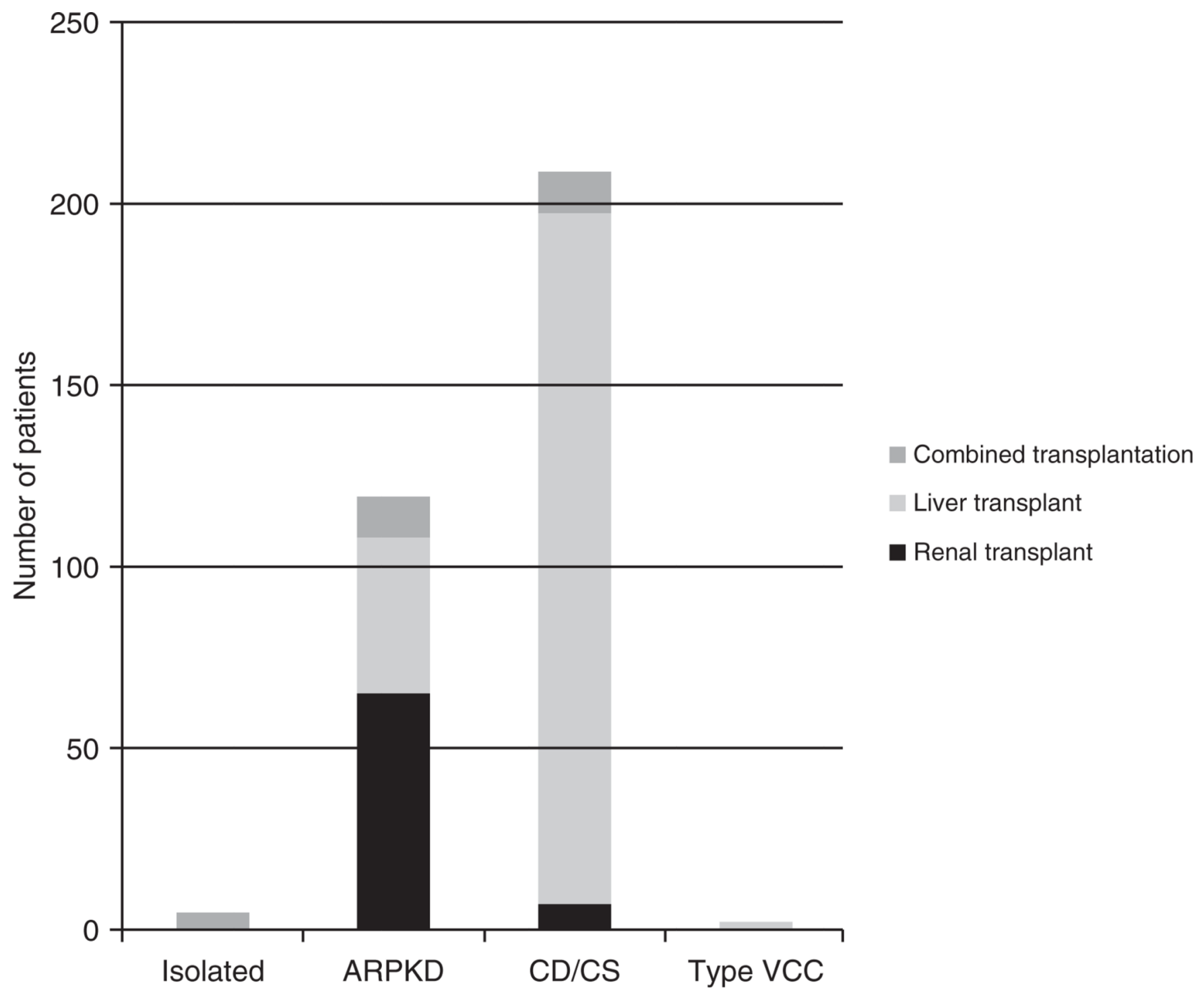

FIGURE 2.

Transplantation in congenital hepatic fibrosis. The number of patients, types of transplantation, and disease type are shown. 
TABLE 1

Distribution of conditions associated with CHF

\begin{tabular}{|c|c|c|c|c|}
\hline CHF subtype & $\begin{array}{l}n(\% \text { total } \\
1230 \text { patients })\end{array}$ & $\begin{array}{l}\text { Mean age at diagnosis, y; } \\
\text { no. reported (median, range, } \\
\text { standard deviation) }\end{array}$ & $\begin{array}{l}\text { Diagnostic modality } \\
N(\%)\end{array}$ & $\begin{array}{l}\text { Most common presenting } \\
\text { symptom/condition N (\%) }\end{array}$ \\
\hline Isolated CHF & $118(9.5)$ & $17.8 ; 37(12,0.3-67,16.6)$ & $\begin{array}{l}79 \text { reported } \\
\text { Liver biopsy: } 79 \text { (100) }\end{array}$ & $\begin{array}{l}43 \text { reported }{ }^{*}, \dagger \\
\text { Portal hypertension: } 16(37) \\
\text { GI bleeding: } 13(30) \\
\text { Cholangitis: } 5(12)\end{array}$ \\
\hline ARPKD & $788(64)$ & $2.5 ; 150(0,0-37,6.2)$ & $\begin{array}{l}184 \text { reported } \\
\text { Liver Biopsy: } 61 \text { (33) } \\
\text { Liver biopsy + renal imaging } \\
\text { (ultrasound, IVP): } 11 \text { (6) } \\
\text { Renal biopsy: } 39(21) \\
\text { Renal biopsy + imaging (U/S): } \\
\text { 12 (7) } \\
\text { Liver and kidney biopsy: } 17 \text { (9) } \\
\text { Imaging alone (IVP, CT, } \\
\text { MRCP, U/S): } 23 \text { (13) } \\
\text { Prenatal U/S: } 12(7) \\
\text { Other } \$: 9(5)\end{array}$ & $\begin{array}{l}195 \text { reported } \\
\text { Nephromegaly: } 63(32) \\
\text { Renal insufficiency: } 33 \text { (17) } \\
\text { Abdominal mass/distension: } \\
25 \text { (13) } \\
\text { Portal hypertension: } 24 \text { (12) } \\
\text { Cholangitis: } 13 \text { (7) } \\
\text { GI bleeding: } 12 \text { (6) } \\
\text { Neonatal respiratory distress: } \\
8 \text { (4) }\end{array}$ \\
\hline $\begin{array}{l}\text { Caroli disease/ } \\
\text { syndrome }\end{array}$ & $315(25.6)$ & $22.3 ; 92(20,0-75,19.9)$ & $\begin{array}{l}95 \text { reported } \\
\text { Liver pathology (biopsy, } \\
\text { lobectomy): } 66 \text { (69) } \\
\text { Liver pathology + imaging } \\
\text { (CT, ultrasound, MRCP): } \\
14 \text { (15) } \\
\text { Hepatobiliary imaging } \\
\text { (ERCP, MRCP, PTC, ultrasound): } \\
9 \text { (10): unspecified imaging: } 6 \text { (6) }\end{array}$ & $\begin{array}{l}103 \text { reported// } \\
\text { Cholangitis: } 67(65) \\
\text { Portal hypertension: } 8 \text { (8) } \\
\text { Abdominal distension/mass: } \\
6(6) \\
\text { Nephromegaly: } 4 \text { (4) } \\
\text { Cholelithiasis: } 3 \text { (3) }\end{array}$ \\
\hline Type V CC & $9(<1)$ & $18 ; 5(0,0-45,24.6)$ & $\begin{array}{l}4 \text { reported } \\
\text { Ultrasound: } 3(75) \\
\text { MRCP: } 1 \text { (25) }\end{array}$ & $\begin{array}{l}2 \text { reported } \\
\text { Cholangitis: } 2 \text { (100) }\end{array}$ \\
\hline
\end{tabular}

$\mathrm{ARPKD}=$ autosomal recessive polycystic kidney disease $\mathrm{CHF}=$ congenital hepatic fibrosis; $\mathrm{CT}=$ computed tomography; $\mathrm{ERCP}=$ endoscopic retrograde cholangiopancreatography; IVP = intravenous pyelogram; $\mathrm{MRCP}=$ magnetic resonance cholangiopancreatography; $\mathrm{PTC}=$ percutaneous transhepatic cholangiography.

* Portal hypertension without gastrointestinal bleeding as presenting symptoms. Gastrointestinal bleeding documented to be related to portal hypertension as presenting symptom.

${ }^{\dagger}$ Other presenting symptoms for isolated CHF included (no. patients): family screening (3), abdominal distension (3), fatigue (2), abdominal pain (1).

F Other presenting symptoms for ARPKD included (no. patients): nonspecific urinary symptoms (6), flank pain (3), genetic screening (2 patients), poor growth (2 patients), fever (2), cholestasis (1 patient), glomerulonephritis (1 patient).

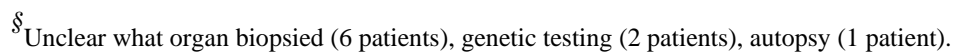

/Other presenting symptoms for CD/CS included (no. patients): jaundice (4), abdominal pain (4), fever (3), gastrointestinal bleeding (2), family screening (2). 


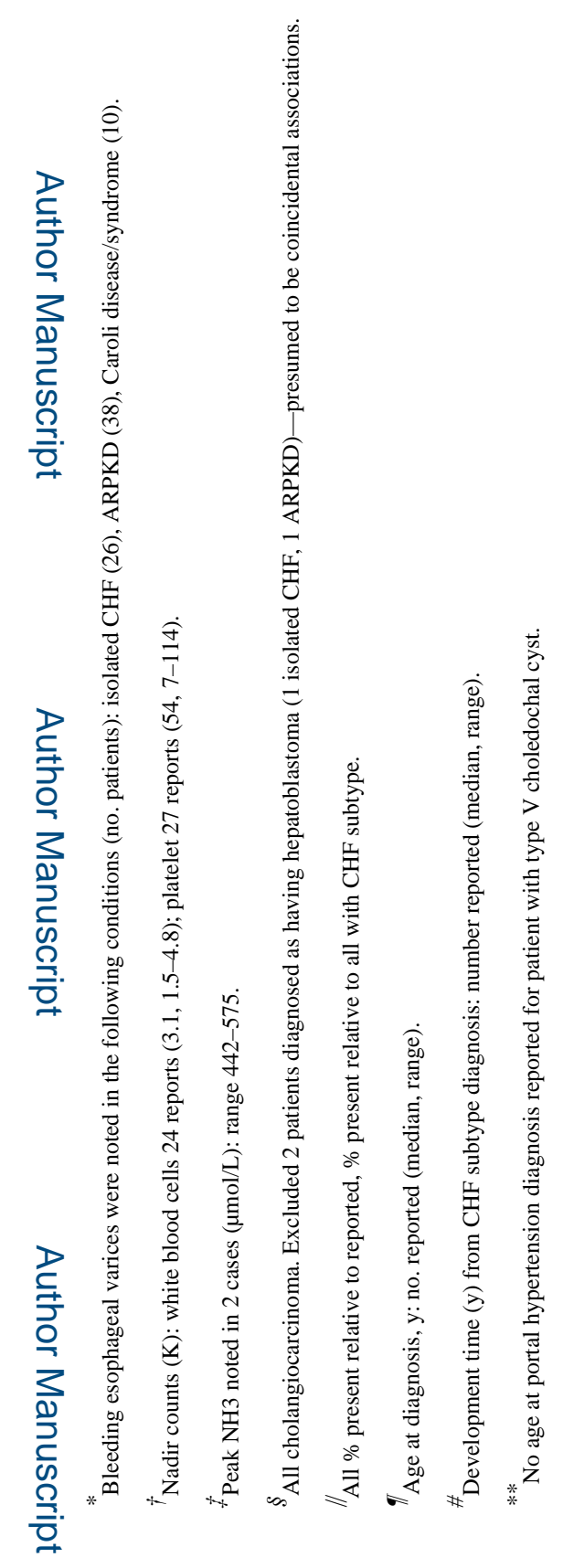

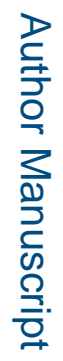

J Pediatr Gastroenterol Nutr. Author manuscript; available in PMC 2015 March 23. 
TABLE 3

Portosystemic shunting in conditions associated with CHF

\begin{tabular}{|c|c|c|c|}
\hline & Portosystemic shunting & $\begin{array}{l}\text { Outcome }{ }^{*} \\
\text { Sample reported (median, range) }\end{array}$ & Shunt type \\
\hline \multirow[t]{2}{*}{ All conditions } & Reported: 259 & & \\
\hline & Presence: 81 & & \\
\hline \multicolumn{4}{|l|}{ CHF subtype } \\
\hline \multirow[t]{6}{*}{ Isolated CHF $(\mathrm{n}=118)$} & Reported: 26 & Reported: 12 & Splenorenal: 13 \\
\hline & Presence: 21 & Improvement: 10 & Distal splenorenal: 8 \\
\hline & $11(9,4.5-20)^{\dagger}$ & $5(1,0.5-3)$ & Proximal splenorenal: 1 \\
\hline & $9(0,0-4.3)^{*}$ & Worsening: 1 & Unspecified splenorenal: 4 \\
\hline & & & Mesocaval: 5 \\
\hline & & & Portocaval: 3 \\
\hline \multirow[t]{6}{*}{$\operatorname{ARPKD}(\mathrm{n}=788)$} & Reported: 216 & Reported: 21 & Splenorenal: 10 \\
\hline & Presence ${ }^{\S}: 57$ & Improvement: 15 & Distal splenorenal: 6 \\
\hline & $24(8,1.9-36)^{\dagger}$ & $7(0.5,0.5-3)$ & Unspecified splenorenal: 4 \\
\hline & $18(4.5,0-27)^{\ddagger}$ & Worsening: 2 & Portocaval: 17 \\
\hline & & $2(1.9,0.7-3)$ & Mesocaval: 6 \\
\hline & & & TIPS: 4 \\
\hline \multirow[t]{4}{*}{ Caroli disease/syndrome $(\mathrm{n}=315)$} & Reported: 17 & Reported: 1 & Splenorenal $/ /: 2$ \\
\hline & Presence: 3 & Improvement: 0 & \\
\hline & $2(10,7-13)^{\dagger}$ & Worsening: 0 & \\
\hline & $2(10,7-13)$ & & \\
\hline \multirow[t]{2}{*}{ Type V CC (n = 9) } & Reported: 0 & 0 & N/A \\
\hline & Presence: 0 & & \\
\hline
\end{tabular}

$\mathrm{ARPKD}=$ autosomal recessive polycystic kidney disease $\mathrm{CC}=$ choledochal cyst $\mathrm{CHF}=$ congenital hepatic fibrosis; $\mathrm{TIPS}=$ transjugular intrahepatic portosystemic shunt.

* Patients without change after portosystemic shunting by condition: isolated CHF (1), ARPKD (4), Caroli disease/syndrome (1).

${ }^{\dagger}$ Age when shunted (y): sample reported (median, range).

* Time to shunt (y) from CHF subtype diagnosis: sample reported (median, range).

$\S$ Only $37 / 57$ portosystemic shunt types noted.

//2/3 portosystemic shunt types noted for Caroli disease/syndrome.

J Pediatr Gastroenterol Nutr. Author manuscript; available in PMC 2015 March 23. 

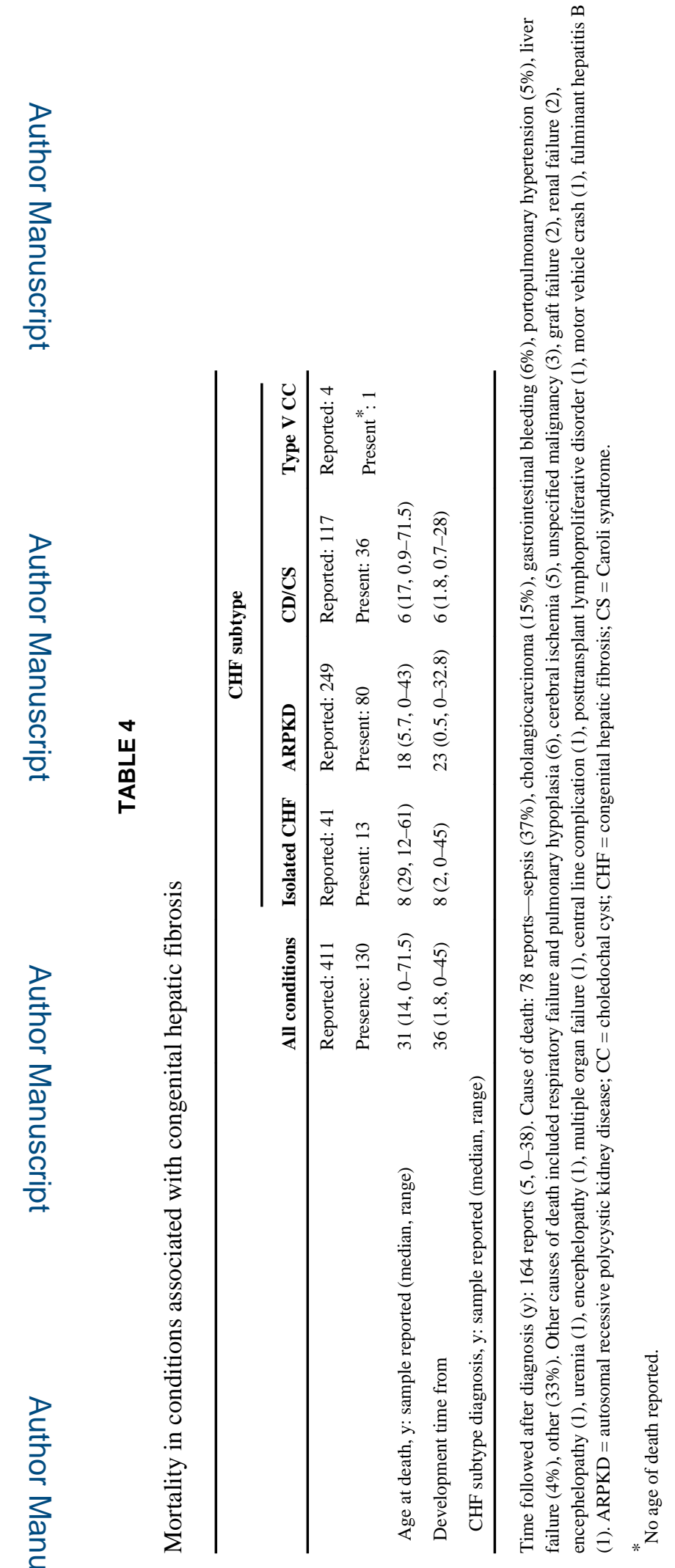

J Pediatr Gastroenterol Nutr. Author manuscript; available in PMC 2015 March 23. 